\title{
Uma reflexão sobre o diálogo instigante e fecundo com o diferente a partir da análise dos filmes Intocáveis e Ela
}

Rosemary Costa, Gabriela Martins, Ana Beatriz Trindade, Stephany Costa, Mariana Rangel ${ }^{1}$

\section{Introdução}

Este trabalho da disciplina Ética Cristã, da Pontifícia Universidade Católica do Rio de Janeiro, é sobre os filmes "Intocáveis" (Intouchables), e "Ela" (Her). O filme "Intocáveis" é de origem francesa, baseado em fatos reais e inspirado no livro autobiográfico de Philippe Pozzo di Borgo, "Le Second souffle". Este longa é uma comédia dramática, escrito por Olivier Nakache e Éric Toledano com François Cluzet e Omar Sy nos principais papeis, lançado no Brasil no ano de 2012, porém já lançado na França em 2011, quando atingiu a marca de filme mais visto do cinema francês. Podemos ressaltar ainda que a renda recebida pelo autor por direitos foi doada para uma associação de deficientes físicos. Vale lembrar que o filme ainda conta com a produção de Nicolas Duval-Adassovsky, Laurent Zeitoun, Yann Zenou.

Já o filme "Ela" é americano, se passa em Los Angeles, num futuro próximo. O filme foi dirigido por Spike Jonze e lançado em fevereiro de 2014. Diferente de "Intocáveis", é um romance dramático, considerado como ficção científica. Os atores Joaquin Phoenix, Amy Adams, Rooney Mara entre outros, protagonizam os personagens, e a voz de Scarlett Johansson, a personagem virtual do filme.

No filme "Intocáveis" ressaltamos a relação entre um multimilionário tetraplégico e um auxiliar de enfermagem que não se enquadra nos padrões convencionais para a função de cuidador desse milionário. O perfil do auxiliar de enfermagem contrasta com o status do paciente, uma vez que o auxiliar é negro, com vida pessoal conturbada, pobre e proveniente da periferia. François Cluzet interpreta um milionário, que teve acesso a viagens e bens próprios de seu padrão econômico mas que, ao sofrer um acidente de parapente, se vê aprisionado em uma cadeira de rodas e sem os próprios movimentos, ou seja, radicalmente dependente de cuidadores. Os enfermeiros/cuidadores o tratavam como um prisioneiro dessa condição, sem possibilidade de viver experiências que abrissem novos horizontes em sua vida pessoal. Até que, neste quadro aparentemente desolador, surge Driss, interpretado por Omar Sy, um negro da periferia, com uma vida conturbada, passagem pela polícia, aparentemente agressivo, que não

\footnotetext{
${ }^{1}$ Rosemary Fernandes da Costa é teóloga, professora do Departamento de Teologia, no Setor de Cultura Religiosa da PUC-Rio e as alunas Gabriela, Ana Beatriz, Stephany e Mariana apresentaram este trabalho como conclusão da disciplina de Ética Cristã, no semestre de 2017.1
} 
se enquadrava aos padrões convencionais para a função de cuidador. A trama se desenvolve em torno de uma mudança dos padrões convencionais que poderiam manter a distância entre os dois personagens, criando aproximações, sensibilidade, companheirismo, confiança e amizade entre os dois.

O filme "Ela" retrata um quadro de amor romântico a partir de uma relação virtual, diferente do que vemos no cotidiano, mas não impossível de se imaginar. O personagem Theodore (Joaquin Phoenix) é um escritor solitário, que adquire um novo sistema operacional para seu computador. Ele se apaixona pela voz deste programa informático, e através de diálogos cada vez mais pessoais e de experiências de convívio virtual, surge uma relação amorosa entre ambos. O roteiro deixa claro o questionamento entre as novas relações entre o ser humano e a tecnologia.

\section{Temática}

Adentrando um pouco mais na temática dos filmes, observamos que no "Intocáveis" o roteiro apresenta o confronto entre duas realidades paradoxais em muitas dimensões: um homem tetraplégico e outro homem com todos os movimentos físicos em plenitude; um aristocrata e um periférico; um branco e um negro. Contudo, nos dois casos, podemos observar uma crise existencial, ou seja, a ausência de perspectivas, de um horizonte de sentido. Esse é o link que une os dois personagens e sobre o qual se estrutura a sua aproximação. O preconceito social, a distância econômica e cultural, não impede esta aproximação, ao contrário, é a riqueza presente na vida de cada personagem que constrói a empatia, a simpatia, a amizade entre os dois.

Nos dois personagens a ausência de perspectivas futuras é também o que promove a abertura para novas experiências, pois nenhum dos dois tem nada a perder, estão desprendidos. O milionário não suporta mais a piedade de seus familiares e contrata Driss justamente para mudar esse padrão de insuficiência e inferioridade.

No filme "Ela", Theodore também está em um momento de crise existencial. Após uma desilusão amorosa o cotidiano do personagem se reduz a uma repetição sem sabor e sem sentido, isso é, vai de seu trabalho para casa, joga na internet, repete automaticamente seus dias e, raramente, encontra uma amiga, seu único momento de diálogo interpessoal. Segue sempre infeliz até que essa rotina é alterada quando decide comprar um sistema operacional, que se torna ajudante, amiga e amante.

O contexto do filme "Ela" é futurístico, em uma sociedade na qual a tecnologia está ainda mais avançada. Para escrever as cartas, o ator principal não usa canetas, e nem a digitação, e sim a própria voz é "lida" pelo sistema e o computador transcreve sua fala; os aparelhos celulares foram substituídos por um pequeno aparelho auditivo, sem fios, conectado a outro pequeno 
aparelho, apenas para a visualização. Os jogos eletrônicos não necessitam mais de controles remotos, pois a própria pessoa, tem seus movimentos "lidos" e passa a "interpretar" um personagem do jogo virtual.

Ao fazer o download do novo sistema operacional, Theodore responde a questões de ordem pessoal e o sistema passa a operar, de forma que possa existir uma interação entre os dois. Theo escolhe que sua inteligência artificial venha na voz de uma mulher, que se identifica como Samantha. Pouco a pouco, o cotidiano de Theo vai sendo cada vez mais ocupado pelo relacionamento virtual, e este sistema expressa características humanas muito aguçadas, como vontades, desejos e sentidos. A relação se aprofunda a ponto de Theo apresentar o sistema operacional, ou seja, Samantha, como namorada.

Em um momento da narrativa, o software de Samantha precisa ser atualizado e, com isso, Theodore perde o contato com a personagem virtual que 'deu sentido à sua vida'. Theo se desespera e, mais adiante, já com o sistema atualizado, Samantha retorna, mas revela que conversa com outros humanos, e está apaixonado por mais de seiscentas pessoas. Essa revelação desestabiliza Theodore, seguida de outra, de que todos os sistemas operacionais daquele modelo seriam desligados. Enfim, sua relação virtual chegava ao fim.

Neste enredo há uma relação real, com a amiga Amy, que também havia estabelecido uma relação de amizade com um sistema operacional e que, igualmente, sente falta desta companhia virtual.

A partir destes quadros cinematográficos, abordaremos três questões éticas. A primeira diz respeito aos relacionamentos, à busca de uma relação dialógica, na qual a diferença de identidades se faz presente e determina o encaminhamento das relações. A segunda, sobre as funções de cada personagem; no "Intocáveis", profissional e amigo se encontram, e no "Ela", um personagem que trabalha escrevendo cartas em nome de outras pessoas, se colocando no lugar delas, e sem vida própria. Em terceiro lugar, as relações sociais, suas convenções, conceitos e preconceitos, novas relações com a tecnologia, o que nos conecta e o que nos desconecta de nós mesmos e do sentido de viver. Enfim, para onde estamos caminhando? Para a conexão conosco mesmos e com outros seres humanos, ou para a desconexão com nossa subjetividade e para o isolamento radical?

\section{Abordagem ética}

No filme "Intocáveis", o cotidiano do relacionamento entre os dois personagens tão diferentes é demarcado no roteiro, e esse cotidiano é que vai tecendo o relacionamento, convidando o espectador a acompanhar essa mudança de ótica, de visão da parte dos dois personagens, mas também da parte dos observadores, sejam os criados do aristocrata, seja da própria família e amigos. A relação entre os dois é tão inusitada que provoca uma revisão nos 
olhares dos que estão entorno.

Philippe percebe que tinha muita coisa para ensinar para Driss como alguns conceitos, avaliação das ações morais, contemplação de formas de arte, pintura, música. Driss, por sua vez, também compartilha novas visões com Philippe, afetivas, sexuais, experiências de lazer e até reações morais diante dos acontecimentos cotidianos. Os dois se percebem aprendendo juntos, crescendo pessoalmente na solidariedade e afeto mútuo. O medo que prendia Philippe à sua condição física e sempre reservada vai dando lugar à confiança, à autoestima, ao resgate dos seus prazeres. Driss é apoiado por Philippe para novas experiências, chega a pintar uma tela que o próprio Philippe apresenta e consegue um valor considerável para a tela de um iniciante, graças às suas recomendações. Quando pede demissão de sua função de cuidador para construir um novo percurso profissional, a amizade dos dois é solidificada e não depende mais da convivência cotidiana.

Dalai Lama, em seu livro "Uma ética para o novo milênio", reflete sobre o julgamento moral, que pode avaliar pessoas como boas ou ruins. No filme "Intocáveis", este tema está presente, pois o preconceito inicial de que Driss está fora dos padrões convencionais para a função é totalmente revisitado ao longo da narrativa. Dalai Lama não define o ser humano como bom ou ruim, e convida a ver o ser humano em suas possibilidades, oportunidades, caminhos de felicidade que vão sendo trilhados. Ao deixar de lado essas categorias, abre-se a chance de ver o potencial em cada ser humano, compreender suas razões e também apoiar suas possibilidades.

O mesmo ocorre com o personagem de Philippe que, ao se relacionar com a alteridade radical de Driss, também oferece os saberes, os privilégios econômicos e a cultura que desenvolveu ao longo de sua vida. Da mesma forma, como já consideramos acima, Driss oferece ao aristocrata uma nova visão do mundo, e potencializa emoções e possibilidades antes adormecidas em Philippe.

No filme "Ela" há um forte diagnóstico da falta de interação entre as pessoas, o isolamento dos personagens é processual, assim como o recurso à tecnologia não apenas como ferramenta de apoio, mas como dependência afetiva e existencial. O que a tecnologia chama de conexão, analisamos aqui neste trabalho, como desconexão, pois observamos que cada personagem está desconectado não apenas de si mesmo, mas dos demais seres humanos com os quais 'esbarra'. A convivência real é substituída pela relação virtual, só que configura uma grande ilusão relacional, pois sem a presença real da alteridade humana, também não há o desenvolvimento e o autoconhecimento da subjetividade.

A inteligência artificial ganhou vida e nesse momento é pertinente trazer as reflexões do Papa Francisco, em sua Exortação Amoris Laetitia, na qual trabalha as relações familiares e afetivas. A fragilidade das relações afetivas e amorosas expressas no filme são objeto de análise 
do Papa Francisco. Nesta Exortação Apostólica, o Papa mostra que as famílias estão se tornando ilhas, cada pessoa está cada vez mais se isolando em seu quarto, com suas tecnologias e esquecendo do mundo real: "às vezes o individualismo destes tempos leva a fechar-se na segurança dum pequeno ninho e a sentir os outros como um incômodo. Todavia este isolamento não proporciona mais paz e felicidade, antes fecha o coração da família e priva-a do horizonte amplo da existência." (AL 187)

Ainda falando sobre o filme "Ela", podemos observar que quando os diálogos tratam das relações virtuais, inclusive com emoções amorosas, não há dificuldades de aceitação ou intolerância. Os personagens acolhem essa nova forma de relacionamento, com sistemas operacionais, com inteligências artificiais, como parte do novo cenário de suas vidas. Contudo, voltamos a enfatizar que se trata de um fetiche, de uma fantasia, que provoca a alienação da subjetividade humana e das relações interpessoais, fundamentais para a humanização e para a saúde. Ou seja, substituir as relações humanas reais por relações virtuais, pode nos conduzir a uma patologia coletiva, ao isolamento, a vários mecanismos ilusórios e fantasiosos, mas não saudáveis e não humanizantes.

No filme "Ela", uma personagem parece romper com esta lógica, que é a ex-esposa de Theodore, que se mostra indignada com a revelação de que ele está se relacionando com um sistema operacional. É a pontuação ética-crítica dentro do roteiro aparentemente inquestionável. Catherine, a ex-esposa, percebe que é um relacionamento cômodo, já que o sistema operacional não interpela, não reflete, não critica, já que ele se alimenta dos dados que o próprio sistema oferece sobre a vida pessoal de Theodore. Mais uma vez, trazemos as palavras do Papa Francisco: "Com efeito, quando não se sabe que fazer com o tempo partilhado, um ou outro dos cônjuges acabará por se refugiar na tecnologia, inventará outros compromissos, buscará outros braços, ou escapará duma intimidade incômoda." (AL 225)

Com elementos de solidão, depressão e isolacionismo, o filme "Ela" nos mostra que é possível chegar o dia em que a tecnologia se transformará em algo além de uma ferramenta. $O$ preocupante é pensar que ela pode até criar a ilusão de substituir pessoas e seus relacionamentos fundamentais. O filme se encerra com Theodore e Amy contemplando o por do sol, pode ser visto como uma alusão ao relacionamento real, não virtual, com a natureza, com outro vínculo também imprescindível para os seres humanos e que também estamos perdendo, enfim, nos desconectando processualmente de tudo que nos realiza verdadeiramente.

Em ambos os filmes, tanto em "Intocáveis" quanto em "Ela", é possível enxergar que existem diversas formas de relacionamentos e que ainda assim eles são questionados e estereotipados. Philippe com Driss viviam a desconfiança inicial dos outros empregados da casa, por terem situações econômicas completamente diferentes; Theodore e Samantha viviam um amor virtual. Ainda assim é possível reparar que em momentos de solidão, Philippe (de 
Intocáveis) e Theodore (de Ela) encontraram companhias inusitadas, que não os julgavam por estarem em um período ruim da vida e que demonstravam estar dispostos a ajudarem, seja de forma profissional-amiga (Driss, de Intocáveis) ou virtual-romântica (Samantha, de Ela).

Em nosso processo de discernimento ético, desenvolvido ao longo das aulas desse semestre, pudemos constatar o quanto as relações dialógicas são fundamentais para cada ser humano, não apenas as relações interpessoais, mas também as ambientais, sociais, econômicas. Nossas escolhas são as possíveis a cada momento, mas também podemos estar atentos nesse processo de reflexão que nos conduz à ética pessoal, relacional e ambiental. Ou seja, o questionamento ético é também um questionamento filosófico, espiritual, de sentido do viver em nossa responsabilidade pessoal e solidária.

\section{Referências Bibliográficas:}

DALAI LAMA. Uma ética para o Novo milênio. Rio de Janeiro: Cip Brasil, 1999 PAPA FRANCISCO. Exortação apostólica pós-sinodal Amoris Laetitia. Vaticano: Editrice Vaticana, 2016. Disponível em

http://w2.vatican.va/content/francesco/pt/apost_exhortations/documents/papafrancesco_esortazione-ap_20160319_amoris-laetitia.html 